\title{
The Role of Genetic Factors and Kidney and Liver Function in Glycemic Control in Type 2 Diabetes Patients on Long-Term Metformin and Sulphonylurea Cotreatment
}

\author{
Jasna Klen, ${ }^{1}$ Katja Goričar, ${ }^{2}$ Andrej Janež, ${ }^{3}$ and Vita Dolžan ${ }^{2}$ \\ ${ }^{1}$ General Hospital Trbovlje, Rudarska cesta 9, 1420 Trbovlje, Slovenia \\ ${ }^{2}$ Pharmacogenetics Laboratory, Institute of Biochemistry, Faculty of Medicine, University of Ljubljana, \\ Vrazov trg 2, 1000 Ljubljana, Slovenia \\ ${ }^{3}$ Department of Endocrinology, Diabetes and Metabolic Diseases, University Medical Center Ljubljana, Zaloška cesta 2, \\ 1000 Ljubljana, Slovenia \\ Correspondence should be addressed to Vita Dolžan; vita.dolzan@mf.uni-lj.si
}

Received 28 February 2014; Revised 18 May 2014; Accepted 21 May 2014; Published 9 June 2014

Academic Editor: Tomohito Gohda

Copyright ( 2014 Jasna Klen et al. This is an open access article distributed under the Creative Commons Attribution License, which permits unrestricted use, distribution, and reproduction in any medium, provided the original work is properly cited.

\begin{abstract}
This study investigated the influence of genetic polymorphisms of metformin transporters on long-term glycemic control and lipid status in type 2 diabetes patients in the everyday clinical setting. In total 135 patients treated with combination of metformin and sulphonylurea for at least 6 months were genotyped for SLC22A1 rs628031 and SLC47A1 rs2289669 polymorphisms. Relatively good blood glucose control with median HbAlc 6.9 (6.4-7.6) \% was achieved on prescribed metformin dosage of 2550 (2000-2550) mg per day. Only 28 (20.7\%) patients experienced mild hypoglycemia events, while no severe hypoglycemia events were observed. Most patients had normal or mildly impaired renal function. Parameters indicating renal function were not correlated with fasting glucose, HbA1c, or lipid parameters. Rs628031 and rs2289669 had minor allele frequencies of 0.385 and 0.355 , respectively, and were not associated with HbA1c levels. Rs628031 was marginally associated with risk for hypoglycemia events $(P=0.046 ; \mathrm{OR}=0.51 ; 95 \%$ CI 0.26-0.99), while significant correlation was observed between rs2289669 and total cholesterol levels $(P=0.018)$. In conclusion, in patients on long-term metformin and sulphonylurea combination treatment, metformin transporters polymorphisms do not play a major role in glycemic control; however, they may influence lipid status.
\end{abstract}

\section{Introduction}

Metformin has been most commonly used as first line therapy for treatment of type 2 diabetes (T2D) for decades, due to both its good antihyperglycemic effect and safety profile [1].

Metformin directly and indirectly inhibits gluconeogenesis and lipid and cholesterol biosynthesis in the liver. It enters hepatocytes via organic cation transporter 1 (OCT1) and decreases ATP production via inhibition of mitochondrial respiration chain. Increased AMP levels trigger activation of AMP-activated protein kinase (AMPK) resulting in decreased glucose production and inhibition of lipid synthesis and increased fatty acid oxidation in the liver. It also leads to increased glucose uptake in muscle and hepatic cells $[2,3]$.
A considerable interindividual variability in glucose lowering response to metformin was reported with reduction of hemoglobin $A_{1 c}$ (HbAlc) values ranging from $0.8 \%$ to $3 \%$. Furthermore, less than two-thirds of patients respond adequately to metformin and achieve a desired fasting glucose level [4]. Both nongenetic and genetic factors may be determinants of metformin effect. Among nongenetic factors, renal and liver functions are probably the most important factors influencing metformin effect [5], while pharmacogenetic studies have been focusing on gene variants related to metformin pharmacokinetics $[6,7]$.

Metformin is not metabolized, so drug transporters have the major role in its pharmacokinetics [8]. Organic cation transporters 1 and 2 (OCT1, OCT2), encoded by SLC22A1 and $S L C 22 A 2$ genes, are the major transporters involved in 
the intestinal absorption, hepatic uptake, and tubular reabsorption of metformin $[7,9,10]$. Multidrug and toxin extrusion protein 1 (MATE 1) encoded by SLC47A2 participates in metformin excretion through the bile and urine and is also involved in pharmacokinetics of metformin [11-13].

Several variants resulting in amino acid substitutions were shown to reduce metformin uptake via OCT1 in cellbased models $[6,14,15]$ and influence metformin pharmacokinetics $[9,16]$; however, most of these variants are very rare not only in Caucasian populations but also in other races $[5,6,17,18]$. SLC22A1 rs628031 p.Met408Val is the most common polymorphism in Caucasian populations $[16,18,19]$. Although it was not shown to alter OCT1 mRNA expression levels or the activity of the transporter, it was associated with clinical effectiveness of metformin $[15,19,20]$.

The effect of metformin transporters on treatment outcome still remains contradictory and even GWAS studies found no significant associations between polymorphisms in genes coding for metformin transporters and metformin response [21].

The aim of this study was to investigate the influence of common genetic polymorphisms in two metformin transporters on glycemic control and lipid status in T2D patients with defined renal and liver function in the everyday clinical setting.

\section{Patients and Methods}

2.1. Patients. Our prospective study included patients with T2D treated with combination of metformin and sulphonylurea at the General Hospital Trbovlje, Slovenia, for at least 6 months. Diagnosis of type 2 diabetes was based on the World Health Organization/American Diabetes Association definition of diabetes $[22,23]$. Patients with diabetes type 1 , gestational diabetes, other types of diabetes, active cancer, heart failure New York Heart Association (NYHA) 3-4, cotreatment with corticosteroids or estrogens, conditions that can cause hyperglycemia, addiction to alcohol or illegal drugs, and dementia or severe psychiatric disorders were not eligible for the study.

The study was approved by the Slovenian Ethics Committee for Research in Medicine and conducted in accordance with the Declaration of Helsinki. Written informed consent was obtained from all the subjects.

Information on the history of diabetes, presence of arterial hypertension, hyperlipidemia and chronic microvascular and macrovascular diabetic complications, smoking status, and concomitant diseases was obtained from the interview at the inclusion in the study and from the medical records. All subjects underwent a physical examination; blood pressure, body height, and body weight were measured and the body mass index (BMI) was calculated.

Glucose-monitoring devices were provided to all the patients participating in the study and they were carefully instructed on their use. All the patients were asked to measure fasting blood glucose levels once per week and additionally at any signs and symptoms suggesting low blood glucose for three months [24].
In all the patients glucose, HbAlc, lipid profile, liver enzymes, urea, creatinine, and estimated glomerular filtration rate (eGF) were determined in a fasting blood sample. At the same visit, microalbuminuria and albumin/creatinine ratio were determined in urine samples.

HbAlc was determined using immunoturbidimetric haemolytic automated analysis of $10 \mu \mathrm{L}$ capillary blood on Hitachi 912 (Hitachi, Japan). All other laboratory parameters were measured using standard laboratory procedure in the biochemistry laboratory of the General Hospital Trbovlje, Slovenia.

Hypoglycemia was defined as symptoms suggestive of low blood glucose confirmed by self-monitored blood glucose measurement below $3.9 \mathrm{mmol} / \mathrm{L}$. Hypoglycemia events were classified into five groups according to American Diabetes Association criteria: (1) severe hypoglycemia, (2) documented symptomatic hypoglycemia, (3) asymptomatic hypoglycemia, (4) probable symptomatic hypoglycemia, and (5) relative hypoglycemia $[25,26]$. Severe hypoglycemia was defined as any episode requiring assistance of another party. Groups 2 to 5 were considered as mild hypoglycemia events. The target HbAlc was defined as value lower than $7.0 \%$. Albuminuria was classified as normal $(<20 \mathrm{mg} / \mathrm{L})$, moderately increased albuminuria $(20-200 \mathrm{mg} / \mathrm{L})$, and severely increased albuminuria (>200 mg/L). eGF was calculated according to the MDRD formula [27] and kidney function was assessed in line with the revised chronic kidney disease classification [28].

2.2. Genotyping. For each patient, $3-5 \mathrm{~mL}$ of peripheral blood was collected into test tubes with EDTA. Plasma was separated and stored at $-80^{\circ} \mathrm{C}$, and the cellular part of the blood sample was stored for a short term at $-20^{\circ} \mathrm{C}$ until DNA isolation. Genomic DNA was isolated from peripheral blood leukocytes using Qiagen FlexiGene kit (Qiagen, Hilden, Germany). Genotyping of SLC22A1 (OCT1) rs628031 G>A (p.Met408Val) and SLC47A1 (MATE1) rs2289669 G>A polymorphisms was carried out using a fluorescence-based competitive allele-specific (KASPar) assay according to the manufacturer's instructions (KBiosciences, Herts, UK).

2.3. Statistical Analysis. Median and interquartile range were used to describe central tendency and variability of continuous variables, while frequencies were used to describe the distribution of categorical variables. Fisher exact test or nonparametric Mann-Whitney test was used to compare clinical characteristics between different patient groups. The chi-square test was used to assess deviation from HardyWeinberg equilibrium (HWE). Logistic regression analysis was performed to assess the effects of the investigated factors on the occurrence of hypoglycemia episodes. Nonparametric tests were used to determine the influence of polymorphisms on continuous parameters, while nonparametric correlations were used for determining correlations between two continuous parameters. Univariate general linear model was used for determining the combined effect of two categorical variables on normally distributed logarithmic values of cholesterol level. The level of statistical significance was set to 0.05 . 
TABle 1: Patients' clinical characteristics.

\begin{tabular}{|c|c|c|c|c|}
\hline & All patients $(N=135)$ & $\begin{array}{l}\text { Not treated with } \\
\text { statins }(N=47)\end{array}$ & $\begin{array}{l}\text { Treated with statins } \\
\qquad(N=88)\end{array}$ & $P$ \\
\hline Gender: male/female [number (\%)] & $78(57.8) / 57(42.2)$ & $27(57.4) / 20(42.6)$ & $51(58.0) / 37(42.0)$ & $1.000^{\mathrm{a}}$ \\
\hline Age (years) [median $(25 \%-75 \%)]$ & $64(59-70)$ & $64(57-70)$ & $65(60-70)$ & $0.310^{\mathrm{b}}$ \\
\hline BMI $\left(\mathrm{kg} / \mathrm{m}^{2}\right)[$ median $(25 \%-75 \%)]$ & $29(28-34)$ & $29(28-32)$ & $30(28-34)$ & $0.545^{\mathrm{b}}$ \\
\hline $\mathrm{BMI}>30[$ number $(\%)]$ & $55(40.7)$ & $16(34.0)$ & $39(44.3)$ & $0.274^{\mathrm{a}}$ \\
\hline $\mathrm{BMI}>35[$ number $(\%)]$ & $23(17.0)$ & $6(12.8)$ & $17(19.3)$ & $0.354^{\mathrm{a}}$ \\
\hline Duration of diabetes (years) [median $(25 \%-75 \%)]$ & $11(6-16)$ & $11(5-16)$ & $10(7-15)$ & $0.967^{\mathrm{b}}$ \\
\hline $\begin{array}{l}\text { Duration of metformin treatment (years) [median } \\
(25 \%-75 \%)]\end{array}$ & $5(4-8)$ & $5(3-8)$ & $6(4-8)$ & $0.487^{\mathrm{b}}$ \\
\hline Metformin dose (mg) [median (25\%-75\%)] & $2550(2000-2550)$ & $2550(1700-2550)$ & $2550(2000-2550)$ & $0.202^{\mathrm{b}}$ \\
\hline HbAlc (\%) [median $(25 \%-75 \%)]^{\mathrm{d}}$ & $6.9(6.4-7.6)$ & $6.7(6.2-7.7)$ & $6.9(6.5-7.6)$ & $0.424^{\mathrm{b}}$ \\
\hline Glucose $(\mathrm{mmol} / \mathrm{L})[\operatorname{median}(25 \%-75 \%)]^{\mathrm{e}}$ & $7.5(6.7-8.8)$ & $7.6(6.7-8.8)$ & $7.5(6.7-8.8)$ & $0.854^{\mathrm{b}}$ \\
\hline Patients with hypoglycemia [number (\%)] & $28(20.7)$ & $7(14.9)$ & $21(23.9)$ & $0.269^{\mathrm{a}}$ \\
\hline Serum creatinine $(\mu \mathrm{mol} / \mathrm{L})[$ median $(25 \%-75 \%)]$ & $75(64-87)$ & $83(64-91)$ & $73(63.3-83)$ & $0.115^{\mathrm{b}}$ \\
\hline $\mathrm{eGF}(\mathrm{mL} / \mathrm{min})[$ median $(25 \%-75 \%)]$ & $82(68-90)$ & $78(66-90)$ & $84(68.3-90)$ & $0.473^{\mathrm{b}}$ \\
\hline Urea $(\mathrm{mmol} / \mathrm{L})[$ median $(25 \%-75 \%)]$ & $5.4(4.4-6.6)$ & $5.3(4.4-6.9)$ & $5.4(4.3-6.4)$ & $0.872^{\mathrm{b}}$ \\
\hline Albuminuria (mg/L) [median $(25 \%-75 \%)]$ & $9(3.7-35.7)$ & $7.1(3.7-41.4)$ & $9.5(3.7-35.6)$ & $0.642^{\mathrm{b}}$ \\
\hline AST $(\mu \mathrm{kat} / \mathrm{L})[\operatorname{median}(25 \%-75 \%)]^{\mathrm{c}}$ & $0.41(0.35-0.50)$ & $0.39(0.35-0.51)$ & $0.41(0.35-0.50)$ & $0.785^{\mathrm{b}}$ \\
\hline $\operatorname{ALT}(\mu \mathrm{kat} / \mathrm{L})[\operatorname{median}(25 \%-75 \%)]^{\mathrm{c}}$ & $0.45(0.36-0.62)$ & $0.435(0.36-0.54)$ & $0.48(0.35-0.68)$ & $0.246^{\mathrm{b}}$ \\
\hline GGT $(\mu \mathrm{kat} / \mathrm{L})[$ median $(25 \%-75 \%)]$ & $0.42(0.31-0.77)$ & $0.42(0.32-0.90)$ & $0.42(0.31-0.76)$ & $0.621^{\mathrm{b}}$ \\
\hline Total cholesterol (mmol/L) [median $(25 \%-75 \%)]$ & $4.3(3.8-5.2)$ & $4.8(4-5.6)$ & $4.1(3.8-4.9)$ & $0.016^{\mathrm{b}}$ \\
\hline LDL cholesterol (mmol/L) [median (25\%-75\%)] & $2.4(1.9-3.3)$ & $3(2.1-3.6)$ & $2.3(1.9-2.9)$ & $0.001^{\mathrm{b}}$ \\
\hline HDL cholesterol $(\mathrm{mmol} / \mathrm{L})[\text { median }(25 \%-75 \%)]^{\mathrm{c}}$ & $1.2(1.0-1.4)$ & $1.3(1-1.5)$ & $1.2(1-1.4)$ & $0.342^{\mathrm{b}}$ \\
\hline TAG (mmol/L) [median $(25 \%-75 \%)]$ & $1.6(1.3-2.4)$ & $1.5(1.1-2)$ & $1.8(1.3-2.7)$ & $0.029^{b}$ \\
\hline
\end{tabular}

${ }^{\mathrm{a}}$ Calculated using Fisher exact test; ${ }^{\mathrm{b}}$ calculated using Mann-Whitney $U$ test; ${ }^{\mathrm{c}}$ data missing for 1 patient; ${ }^{\mathrm{d}}$ data missing for 3 patients; ${ }^{\mathrm{e}}$ data for 88 patients $(28$ not treated with statins and 60 treated with statins).

Data were analysed using IBM SPSS Statistics 19.0 (IBM Corporation, Armonk, NY, USA).

\section{Results}

A total of 135 patients (males and females) were receiving combination treatment with metformin and SU for a median (25\%-75\% range) of $5(4-8)$ years. The characteristics of the patient group are shown in Table 1 . The median age of the patients was 64 (59-70) years. In total $55(40.7 \%)$ patients were moderately obese $(\mathrm{BMI}>30)$, while $32(17.0 \%)$ patients were severely obese with $\mathrm{BMI}>35$.

The average duration of diabetes in the study group was $11(6-16)$ years and was significantly correlated with age $(P=$ 0.007 ). The prescribed metformin dosage was 2550 (20002550) mg per day. On the prescribed treatment regimen most of the patients achieved relatively good blood glucose control with the average HbAlc 6.9 (6.4-7.6) \% (Table 1). The median (25-75\% range) fasting blood glucose levels were 7.5 (6.7$8.8) \mathrm{mmol} / \mathrm{L}$. Only $28(20.7 \%)$ patients experienced a total of 67 mild hypoglycemia events, while no severe hypoglycemia events were observed. Among all hypoglycemia events, 38 (56.7\%) were documented as symptomatic hypoglycemia, 27 (40.3\%) were asymptomatic hypoglycemia, and 2 (3.0\%) were probable symptomatic hypoglycemia.
Most patients had normal or mildly impaired renal function. Regarding the eGF stage, $47(34.8 \%)$ patients belonged to stage $1,74(54.8 \%)$ to stage $2,13(9.6 \%)$ to stage $3 a$, and 1 $(0.7 \%)$ to stage $3 \mathrm{~b}$. In total $88(65.2 \%)$ patients had normal albuminuria, 38 (28.1\%) had moderately increased albuminuria, and 9 (6.7\%) had severely increased albuminuria. Liver function was also normal in most of the patients (Table 1). Significant differences were observed between patients on or without statin treatment regarding total cholesterol $(P=$ 0.016), LDL cholesterol $(P=0.001)$, and TAG $(P=0.029)$, but not for HDL cholesterol $(P=0.342)$ (Table 1$)$.

We observed that age was significantly correlated with rates of glomerular filtration $(P<0.001)$, creatinine levels $(P=0.009)$, and urea levels $(P=0.001)$, while a significant correlation was observed between diabetes duration and glomerular filtration $(P=0.047)$ and creatinine levels $(P=0.001)$. Parameters indicating renal function were not correlated with fasting glucose, HbAlc, or lipid parameters. No other clinical parameters were associated with $\mathrm{HbAlc}$, total cholesterol, or LDL cholesterol. Increased BMI was associated with increased gamma-glutamyl transferase (GGT) $(P=0.042)$ and increased TAG $(P=0.003)$. Increased TAG levels were also associated with increased ALT $(P=$ 0.031). Significant correlations were also observed between increased age and decreased HDL levels $(P=0.020)$. 
TABLE 2: SLC22A1 in SLC47A1 genotype frequencies and the risk for hypoglycemia events.

\begin{tabular}{|c|c|c|c|c|c|c|}
\hline \multirow{2}{*}{ Polymorphism } & \multirow{2}{*}{ Genotype } & \multicolumn{2}{|c|}{ All patients } & \multicolumn{3}{|c|}{ Patients with hypoglycemia } \\
\hline & & $N(\%)$ & MAF & $N(\%)$ & $P$ & OR $(95 \% \mathrm{CI})$ \\
\hline \multirow{3}{*}{$\begin{array}{l}S L C 47 A 1 \\
\text { rs2289669 }\end{array}$} & GG & $54(40.3)$ & \multirow{3}{*}{$0.355^{*}$} & $10(18.5)$ & \multirow{3}{*}{0.310} & \multirow{3}{*}{$1.38(0.74-2.59)$} \\
\hline & GA & $65(48.5)$ & & $13(20.0)$ & & \\
\hline & AA & $15(11.2)$ & & $5(33.3)$ & & \\
\hline \multirow{3}{*}{$\begin{array}{l}S L C 22 A 1 \\
\text { rs628031 }\end{array}$} & GG & $51(37.8)$ & \multirow{3}{*}{0.385} & $15(29.4)$ & \multirow{3}{*}{0.046} & \multirow{3}{*}{$0.51(0.26-0.99)$} \\
\hline & GA & $64(47.4)$ & & $11(17.2)$ & & \\
\hline & AA & $20(14.8)$ & & $2(10.0)$ & & \\
\hline
\end{tabular}

* Data missing for 1 patient; MAF: minor allele frequency.

TABLE 3: SLC22A1 and SLC47A1 polymorphisms and HbAlc levels.

\begin{tabular}{lccc}
\hline Polymorphism & Genotype & $\begin{array}{c}\text { HbAlc } \\
\text { median }(25-75 \%)\end{array}$ & $P^{\mathrm{a}}$ \\
\hline SLC47A1 & GG & $6.7(6.4-7.5)$ & \\
rs2289669 & GA & $7.1(6.5-7.7)$ & 0.222 \\
& AA & $6.7(6.3-7.3)$ & \\
\hline SLC22A1 & GG & $7.0(6.4-7.4)$ & \\
rs628031 & GA & $6.8(6.4-7.7)$ & 0.756 \\
& AA & $6.8(6.5-7.5)$ & \\
\hline
\end{tabular}

${ }^{\mathrm{a} C a l c u l a t e d ~ u s i n g ~ K r u s k a l-W a l l i s ~ t e s t . ~}$

All the patients were genotyped for SLC22A1 rs628031and SLC47A1 rs2289669 polymorphisms and the respective genotype frequencies are shown in Table 2. Both polymorphisms were in HWE with minor allele frequencies (MAF) of 0.385 and 0.355 , respectively.

SLC22A1 rs628031 polymorphism was marginally associated with risk for hypoglycemia events $(P=0.046$; $\mathrm{OR}=0.51$; 95\% CI 0.26-0.99), while SLC47A1 rs2289669 did not influence the risk for hypoglycemia events $(P=0.310)$ (Table 2$)$. The results remained the same even after adjustment for renal function $(P=0.046$ and $P=0.311$ for rs628031 and rs2289669, resp.). The investigated polymorphisms were not associated with HbAlc levels $(P=0.756$ and $P=$ 0.222 for SLC22A1 and SLC47A1, resp.) (Table 3). Adjustment for renal function did not affect the association between polymorphisms and HbAlc. Both polymorphisms were also not correlated with BMI, HDL cholesterol, LDL cholesterol, or TAG, while significant correlation was observed only between SLC47A1 and total cholesterol levels $(P=0.018)$ (Table 4).

Because both SLC47A1 rs2289669 genotype and statin use were associated with cholesterol levels, combined effect on cholesterol was examined using general linear model. As cholesterol levels were not normally distributed, logarithmically transformed values were used in the analysis. Both SLC47A1 rs2289669 genotype $(F(2,128)=3.466 ; P=$ $0.034)$ and statin use $(F(1,128)=6.237 ; P=0.014)$ remained significantly associated with cholesterol levels in T2D patients, treated with metformin, but the interaction was not significant $(F(2,128)=0.943 ; P=0.392)$. Even if the results were adjusted for renal function, SLC47A1

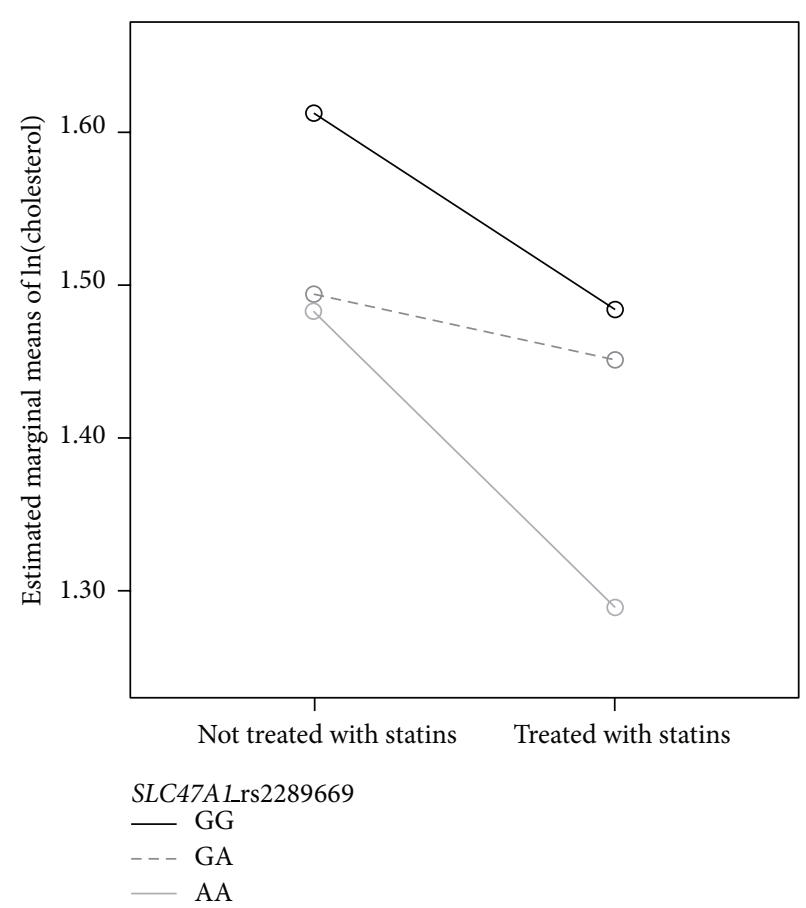

FIGURE 1: The combined effect of SLC47A1 rs2289669 and statin treatment on logarithmically transformed values of cholesterol levels in T2D patients.

rs2289669 $(F(2,127)=3.383$ and $P=0.037)$ and statin use $(F(1,127)=6.348 ; P=0.013)$ significantly influenced cholesterol levels, while renal function was not significantly associated with cholesterol levels $(F(1,127)=0.540$ and $P=0.464)$. Patients with polymorphic SLC47A1 rs2289669 AA genotype who were treated with statins had the lowest cholesterol levels, while patients with SLC47A1 rs2289669 GG genotype not treated with statins had the highest cholesterol levels (Figure 1).

\section{Discussion}

Our study was designed to investigate the influence of genetic polymorphisms of metformin transporters on glycemic control and lipid status in T2D patients with defined renal and liver function in the everyday clinical setting. Patients 
TABLE 4: The influence of SLC22A1 and SLC47A1 polymorphisms on BMI and lipid profile.

\begin{tabular}{|c|c|c|c|c|c|c|c|c|c|c|c|}
\hline Polymorphism & & $\begin{array}{c}\text { BMI } \\
\text { median } \\
(25-75 \%)\end{array}$ & $P^{\mathrm{a}}$ & $\begin{array}{c}\text { Total } \\
\text { cholesterol } \\
\text { median } \\
(25-75 \%)\end{array}$ & $P^{\mathrm{a}}$ & $\begin{array}{c}\text { HDL } \\
\text { cholesterol } \\
\text { median } \\
(25-75 \%)\end{array}$ & $P^{\mathrm{a}}$ & $\begin{array}{c}\text { LDL } \\
\text { cholesterol } \\
\text { median } \\
(25-75 \%)\end{array}$ & $P^{\mathrm{a}}$ & $\begin{array}{c}\text { TAG } \\
\text { median } \\
(25-75 \%)\end{array}$ & $P^{\mathrm{a}}$ \\
\hline \multirow{3}{*}{$\begin{array}{l}S L C 47 A 1 \\
\text { rs2289669 }\end{array}$} & GG & $\begin{array}{c}30.0 \\
(28.0-33.0)\end{array}$ & & $\begin{array}{c}4.6 \\
(3.9-5.5)\end{array}$ & & $\begin{array}{c}1.2 \\
(1.0-1.4)\end{array}$ & & $\begin{array}{c}2.7 \\
(2.0-3.5)\end{array}$ & & $\begin{array}{c}1.7 \\
(1.3-2.7)\end{array}$ & \\
\hline & GA & $\begin{array}{c}29.0 \\
(28.0-34.5)\end{array}$ & 0.835 & $\begin{array}{c}4.5 \\
(3.6-5.0)\end{array}$ & 0.018 & $\begin{array}{c}1.1 \\
(1.0-1.5)\end{array}$ & 0.683 & $\begin{array}{c}2.4 \\
(1.9-3.2)\end{array}$ & 0.070 & $\begin{array}{c}1.6 \\
(1.2-2.4)\end{array}$ & 0.562 \\
\hline & $\mathrm{AA}$ & $\begin{array}{c}29.0 \\
(26.0-35.0) \\
\end{array}$ & & $\begin{array}{c}4.0 \\
(3.4-4.2)\end{array}$ & & $\begin{array}{c}1.1 \\
(1.0-1.3)\end{array}$ & & $\begin{array}{c}2.1 \\
(1.9-2.5) \\
\end{array}$ & & $\begin{array}{c}1.5 \\
(1.4-1.9) \\
\end{array}$ & \\
\hline \multirow{3}{*}{$\begin{array}{l}S L C 22 A 1 \\
\text { rs628031 }\end{array}$} & GG & $\begin{array}{c}29.0 \\
(28.0-34.0)\end{array}$ & & $\begin{array}{c}4.5 \\
(3.8-5.6)\end{array}$ & & $\begin{array}{c}1.2 \\
(1.0-1.4)\end{array}$ & & $\begin{array}{c}2.5 \\
(2.0-3.5)\end{array}$ & & $\begin{array}{c}1.5 \\
(1.2-2.2)\end{array}$ & \\
\hline & GA & $\begin{array}{c}30.0 \\
(27.1-32.0)\end{array}$ & 0.387 & $\begin{array}{c}4.4 \\
(3.8-5.3)\end{array}$ & 0.711 & $\begin{array}{c}1.2 \\
(1.0-1.5)\end{array}$ & 0.096 & $\begin{array}{c}2.4 \\
(1.9-3.2)\end{array}$ & 0.365 & $\begin{array}{c}1.8 \\
(1.3-2.5)\end{array}$ & 0.569 \\
\hline & $\mathrm{AA}$ & $\begin{array}{c}32.5 \\
(28.3-34.0)\end{array}$ & & $\begin{array}{c}4.2 \\
(3.7-4.9)\end{array}$ & & $\begin{array}{c}1.1 \\
(0.9-1.3)\end{array}$ & & $\begin{array}{c}2.4 \\
(1.7-3.1)\end{array}$ & & $\begin{array}{c}1.7 \\
(1.2-2.9)\end{array}$ & \\
\hline
\end{tabular}

${ }^{\mathrm{a}}$ Calculated using Kruskal-Wallis test.

on long-term treatment were included in the study. This is a major difference in design from studies that investigated short-term response to metformin treatment, mostly including patients starting the treatment and evaluating response after a period of treatment [29-31]. T2D is a chronic metabolic disorder mostly requiring a life-long treatment, so it is of considerable interest to also study pharmacogenetic determinants of long-term treatment outcomes [24].

All patients were on metformin and sulphonylurea combination treatment. In general combinations of metformin and sulphonylurea are frequently used in the clinical practice as less than two-thirds of patients achieve the therapeutic goals on monotherapy with metformin [32]. Relatively good HbAlc levels were observed in our study group, although fasting blood glucose levels were mildly increased. As glucose control was not very tight, no severe and very few mild hypoglycemia events were observed despite sulphonylurea and metformin combination treatment. Although metformin does not cause hypoglycemia by itself in combination with sulphonylurea it may result in lower glucose levels and subsequently an increased risk for hypoglycemic events.

Our patient group was carefully checked for the kidney and liver function as metformin is primarily excreted via kidney and liver is its main target organ. Renal function was normal or mildly impaired in the majority of patients, so it was not expected that this could influence metformin pharmacokinetics. Population pharmacokinetic models have shown that metformin can be used also in patients with renal impairment with appropriate dosage adjustments based on the therapeutic drug monitoring [33]. As this is not routinely available in our country, patients with severe impairment of kidney function are not prescribed metformin; besides, this was an exclusion criterion in our study. Parameters indicating renal function were not correlated with fasting glucose, HbAlc, or lipid parameters. Metformin metabolic effects were also not influenced by liver function as it was mostly normal.
Although metformin reduces total and LDL cholesterol levels and increases HDL levels [34], placebo-controlled studies reported no significant effect of metformin treatment on total or HDL cholesterol; however, improvement in TAG levels was observed [3]. Similar to other studies [35], BMI and other clinical characteristics were not associated with glycemic control, total cholesterol, or LDL cholesterol. However, increased BMI was associated with increased TAG levels.

In our study group significant differences were observed between patients on or without statin treatment regarding total cholesterol, LDL cholesterol, and TAG, but not for HDL cholesterol. A placebo-controlled study in poorly controlled T1D patients also observed that metformin therapy significantly lowered total and LDL cholesterol independent of statin therapy [36].

Although some studies reported that SLC47A1 rs2289669 genotype was significantly associated with the reduction in HbAlc after the first 6 months of treatment [30], we observed no influence of the studied metformin transporter polymorphism on long-term glycemic control. This is in agreement with other studies as most observed no association between metformin transporter polymorphisms and HbAlc levels [37].

Different polymorphisms in SLC22A1 were either positively, negatively, or not correlated with treatment response in T2D $[15,16,20,31]$; however, p.Met408Val polymorphism was found to be a positive predictor of metformin efficacy $[20,21]$. Our data indicate that genetic variability of metformin transporters is not the major determinant of the long-term glycemic control, although they may contribute to metabolic effects of metformin treatment. In our study group the investigated SLC22A1 polymorphism was not associated with $\mathrm{HbAlc}$ levels and only marginally associated with risk for hypoglycemia events, while significant correlation was observed between SLC47A1 and total cholesterol levels.

In conclusion, we have shown that in patients on longterm metformin and sulphonylurea combination treatment 
polymorphisms of metformin transporters do not play a major role in glycemic control; however, they may influence lipid status. We have also observed an interesting correlation between SLC47A1 and total cholesterol levels that was independent of statin treatment.

\section{Conflict of Interests}

No competing financial interests exist.

\section{Acknowledgments}

The authors wish to acknowledge the clinical nurse Mrs. Nevenka Kiric for her support with clinical part of the study and Mrs. Savica Soldat, B.S., for her expert technical assistance. This study was financially supported by the Slovenian Research Agency (ARRS nos. P1-0170 and P3-0298).

\section{References}

[1] D. R. Erlich, D. C. Slawson, and A. Shaughnessy, "Diabetes update: long-term treatment of adults," FP Essentials, vol. 408, pp. 14-19, 2013.

[2] G. Rena, E. R. Pearson, and K. Sakamoto, "Molecular mechanism of action of metformin: old or new insights?" Diabetologia, vol. 56, no. 9, pp. 1898-1906, 2013.

[3] H. Y. Sin, J. Y. Kim, and K. H. Jung, "Total cholesterol, high density lipoprotein and triglyceride for cardiovascular disease in elderly patients treated with metformin," Archives of Pharmacal Research, vol. 34, no. 1, pp. 99-107, 2011.

[4] S. E. Inzucchi, R. M. Bergenstal, J. B. Buse et al., "Management of hyperglycaemia in type 2 diabetes: a patient-centered approach. Position statement of the American Diabetes Association (ADA) and the European Association for the Study of Diabetes (EASD)," Diabetologia, vol. 55, no. 6, pp. 1577-1596, 2012.

[5] O. Zolk, "Disposition of metformin: variability due to polymorphisms of organic cation transporters," Annals of Medicine, vol. 44, no. 2, pp. 119-129, 2012.

[6] Y. Shu, C. Brown, R. A. Castro et al., "Effect of genetic variation in the organic cation transporter 1, OCT1, on metformin pharmacokinetics," Clinical Pharmacology and Therapeutics, vol. 83, no. 2, pp. 273-280, 2008.

[7] G. G. Graham, J. Punt, M. Arora et al., "Clinical pharmacokinetics of metformin," Clinical Pharmacokinetics, vol. 50, no. 2, pp. 81-98, 2011.

[8] O. Zolk, "Current understanding of the pharmacogenomics of metformin," Clinical Pharmacology and Therapeutics, vol. 86, no. 6, pp. 595-598, 2009.

[9] M. V. Tzvetkov, S. V. Vormfelde, D. Balen et al., "The effects of genetic polymorphisms in the organic cation transporters OCT1, OCT2, and OCT3 on the renal clearance of metformin," Clinical Pharmacology and Therapeutics, vol. 86, no. 3, pp. 299306, 2009.

[10] E. Lozano, E. Herraez, O. Briz et al., "Role of the plasma membrane transporter of organic cations OCT1 and its genetic variants in modern liver pharmacology," BioMed Research International, vol. 2013, Article ID 692071, 13 pages, 2013.

[11] M. Otsuka, T. Matsumoto, R. Morimoto, S. Arioka, H. Omote, and Y. Moriyama, "A human transporter protein that mediates the final excretion step for toxic organic cations," Proceedings of the National Academy of Sciences of the United States of America, vol. 102, no. 50, pp. 17923-17928, 2005.

[12] M. Tsuda, T. Terada, T. Mizuno, T. Katsura, J. Shimakura, and K.-I. Inui, "Targeted disruption of the multidrug and toxin extrusion 1 (Matel) gene in mice reduces renal secretion of metformin," Molecular Pharmacology, vol. 75, no. 6, pp. 12801286, 2009.

[13] H. Motohashi and K.-I. Inui, "Organic cation transporter OCTs (SLC22) and MATEs (SLC47) in the human kidney," AAPS Journal, vol. 15, no. 2, pp. 581-588, 2013.

[14] R. Kerb, U. Brinkmann, N. Chatskaia et al., "Identification of genetic variations of the human organic cation transporter hOCT1 and their functional consequences," Pharmacogenetics, vol. 12, no. 8, pp. 591-595, 2002.

[15] Y. Shu, S. A. Sheardown, C. Brown et al., "Effect of genetic variation in the organic cation transporter 1 (OCT1) on metformin action," Journal of Clinical Investigation, vol. 117, no. 5, pp. 14221431, 2007.

[16] M. L. Becker, L. E. Visser, R. H. N. van Schaik, A. Hofman, A. G. Uitterlinden, and B. H. C. Stricker, "Genetic variation in the organic cation transporter 1 is associated with metformin response in patients with diabetes mellitus," Pharmacogenomics Journal, vol. 9, no. 4, pp. 242-247, 2009.

[17] L. Chen, M. Takizawa, E. Chen et al., "Genetic polymorphisms in organic cation transporter 1 (OCT1) in Chinese and Japanese populations exhibit altered function," Journal of Pharmacology and Experimental Therapeutics, vol. 335, no. 1, pp. 42-50, 2010.

[18] G. Umamaheswaran, R. G. Praveen, A. S. Arunkumar, A. K. Das, D. G. Shewade, and C. Adithan, "Genetic analysis of OCT1 gene polymorphisms in an Indian population," Indian Journal of Human Genetics, vol. 17, no. 3, pp. 164-168, 2011.

[19] A. T. Nies, H. Koepsell, S. Winter et al., "Expression of organic cation transporters OCT1 (SLC22A1) and OCT3 (SLC22A3) is affected by genetic factors and cholestasis in human liver," Hepatology, vol. 50, no. 4, pp. 1227-1240, 2009.

[20] E. Shikata, R. Yamamoto, H. Takane et al., "Human organic cation transporter (OCT1 and OCT2) gene polymorphisms and therapeutic effects of metformin," Journal of Human Genetics, vol. 52, no. 2, pp. 117-122, 2007.

[21] K. Zhou, C. Bellenguez, C. C. A. Spencer et al., "Common variants near ATM are associated with glycemic response to metformin in type 2 diabetes," Nature Genetics, vol. 43, no. 2, pp. 117-120, 2011.

[22] "Standards of medical care in diabetes-2010," Diabetes Care, vol. 33, supplement 1, pp. S11-S61, 2010.

[23] "Diagnosis and classification of diabetes mellitus," Diabetes Care, vol. 36, supplement 1, pp. S67-S74, 2013.

[24] J. Klen, V. Dolzan, and A. Janez, "CYP2C9, KCNJ11 and ABCC8 polymorphisms and the response to sulphonylurea treatment in type 2 diabetes patients," European Journal of Clinical Pharmacology, vol. 70, no. 4, pp. 421-428, 2014.

[25] P. E. Cryer, "Defining and reporting hypoglycemia in diabetes: a report from the American diabetes association workgroup on hypoglycemia," Diabetes Care, vol. 28, no. 5, pp. 1245-1249, 2005.

[26] E. R. Seaquist, J. Anderson, B. Childs et al., "Hypoglycemia and diabetes: a report of aworkgroup of the American diabetes association and the endocrine society," Diabetes Care, vol. 36, no. 5, pp. 1384-1395, 2013.

[27] A. S. Levey, J. P. Bosch, J. B. Lewis, T. Greene, N. Rogers, and D. Roth, "A more accurate method to estimate glomerular filtration rate from serum creatinine: a new prediction equation," Annals of Internal Medicine, vol. 130, no. 6, pp. 461-470, 1999. 
[28] A. S. Levey, K.-U. Eckardt, Y. Tsukamoto et al., "Definition and classification of chronic kidney disease: a position statement from Kidney Disease: Improving Global Outcomes (KDIGO)," Kidney International, vol. 67, no. 6, pp. 2089-2100, 2005.

[29] M. L. Becker, L. E. Visser, R. H. N. Van Schaik, A. Hofman, A. G. Uitterlinden, and B. H. C. Stricker, "Interaction between polymorphisms in the OCT1 and MATE1 transporter and metformin response," Pharmacogenetics and Genomics, vol. 20, no. 1, pp. 38-44, 2010.

[30] I. Tkáč, L. Klimčáková, M. Javorský et al., "Pharmacogenomic association between a variant in SLC47A1 gene and therapeutic response to metformin in type 2 diabetes," Diabetes, Obesity and Metabolism, vol. 15, no. 2, pp. 189-191, 2013.

[31] K. Zhou, L. A. Donnelly, C. H. Kimber et al., "Reduced-function SLC22A1 polymorphisms encoding organic cation transporter 1 and glycemic response to metformin: a GoDARTS study," Diabetes, vol. 58, no. 6, pp. 1434-1439, 2009.

[32] S. E. Kahn, S. M. Haffner, M. A. Heise et al., "Glycemic durability of rosiglitazone, metformin, or glyburide monotherapy," The New England Journal of Medicine, vol. 355, no. 23, pp. 24272443, 2006.

[33] J. K. Duong, S. S. Kumar, C. M. Kirkpatrick et al., "Population pharmacokinetics of metformin in healthy subjects and patients with type 2 diabetes mellitus: simulation of doses according to renal function," Clinical Pharmacokinetics, vol. 52, no. 5, pp. 373-384, 2013.

[34] A. Kooy, J. De Jager, P. Lehert et al., "Long-term effects of metformin on metabolism and microvascular and macrovascular disease in patients with type 2 diabetes mellitus," Archives of Internal Medicine, vol. 169, no. 6, pp. 616-625, 2009.

[35] L. Ji, H. Li, X. Guo, Y. Li, R. Hu, and Z. Zhu, "Impact of baseline BMI on glycemic control and weight change with metformin monotherapy in Chinese type 2 diabetes patients: phase IV open-label trial," PLoS ONE, vol. 8, no. 2, Article ID e57222, 2013.

[36] S. S. Lund, L. Tarnow, A. S. Astrup et al., "Effect of adjunct metformin treatment on levels of plasma lipids in patients with type 1 diabetes," Diabetes, Obesity and Metabolism, vol. 11, no. 10, pp. 966-977, 2009.

[37] L. Tarasova, I. Kalnina, K. Geldnere et al., "Association of genetic variation in the organic cation transporters OCT1, OCT2 and multidrug and toxin extrusion 1 transporter protein genes with the gastrointestinal side effects and lower BMI in metformin-treated type 2 diabetes patients," Pharmacogenetics and Genomics, vol. 22, no. 9, pp. 659-666, 2012. 


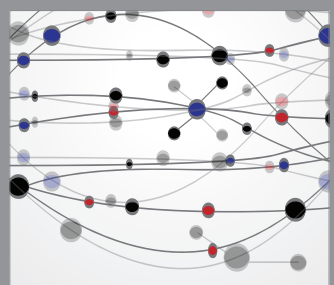

The Scientific World Journal
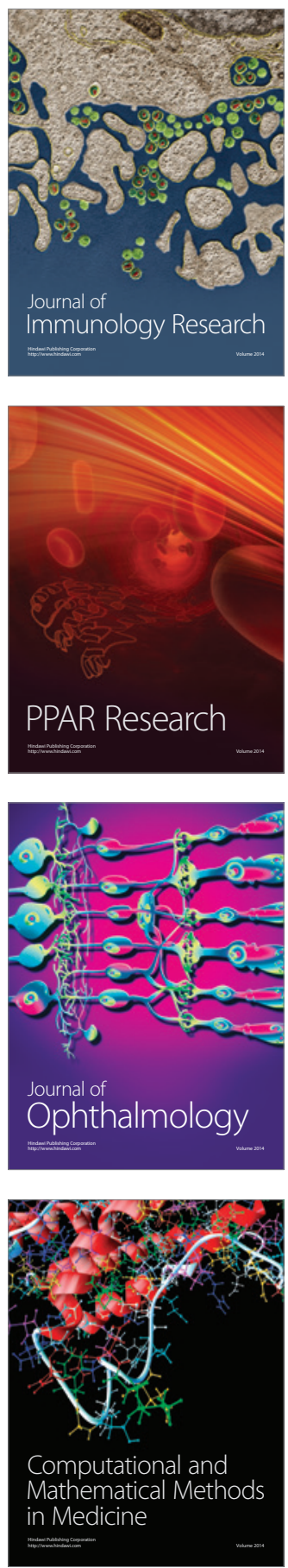

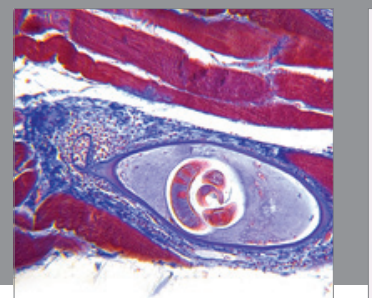

Gastroenterology

Research and Practice
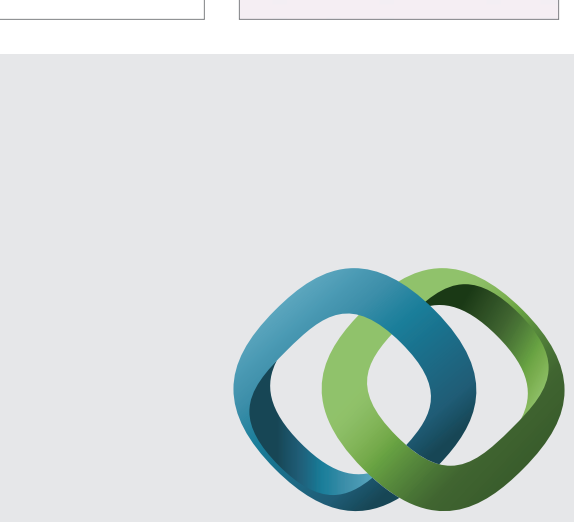

\section{Hindawi}

Submit your manuscripts at

http://www.hindawi.com
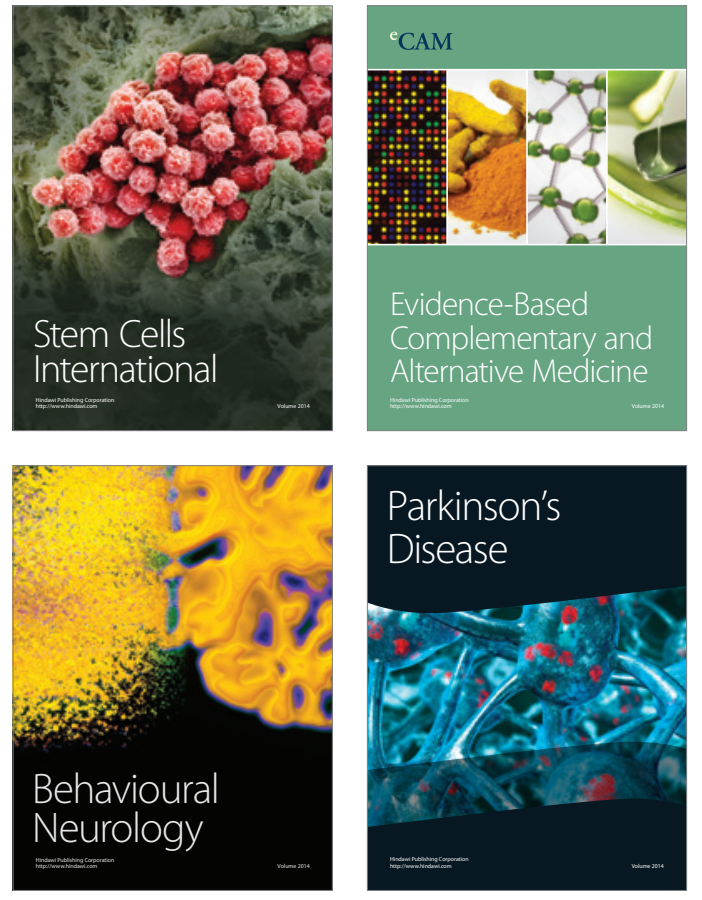
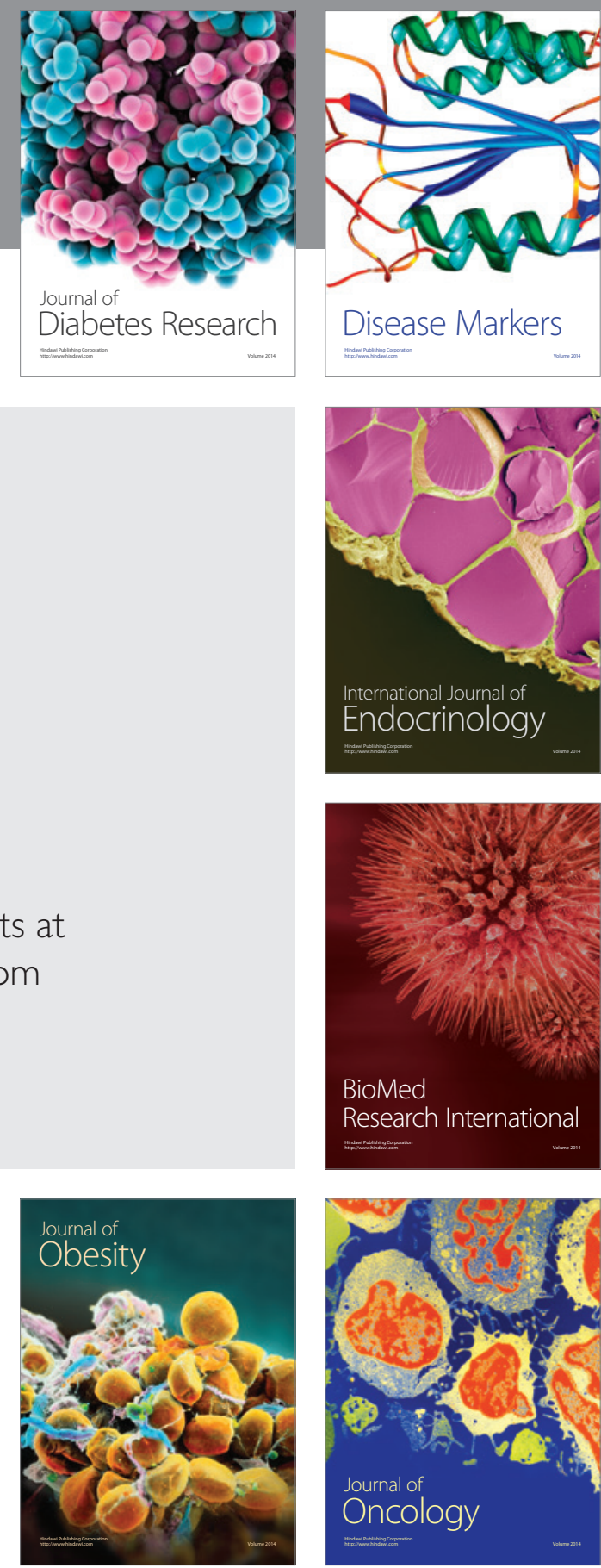

Disease Markers
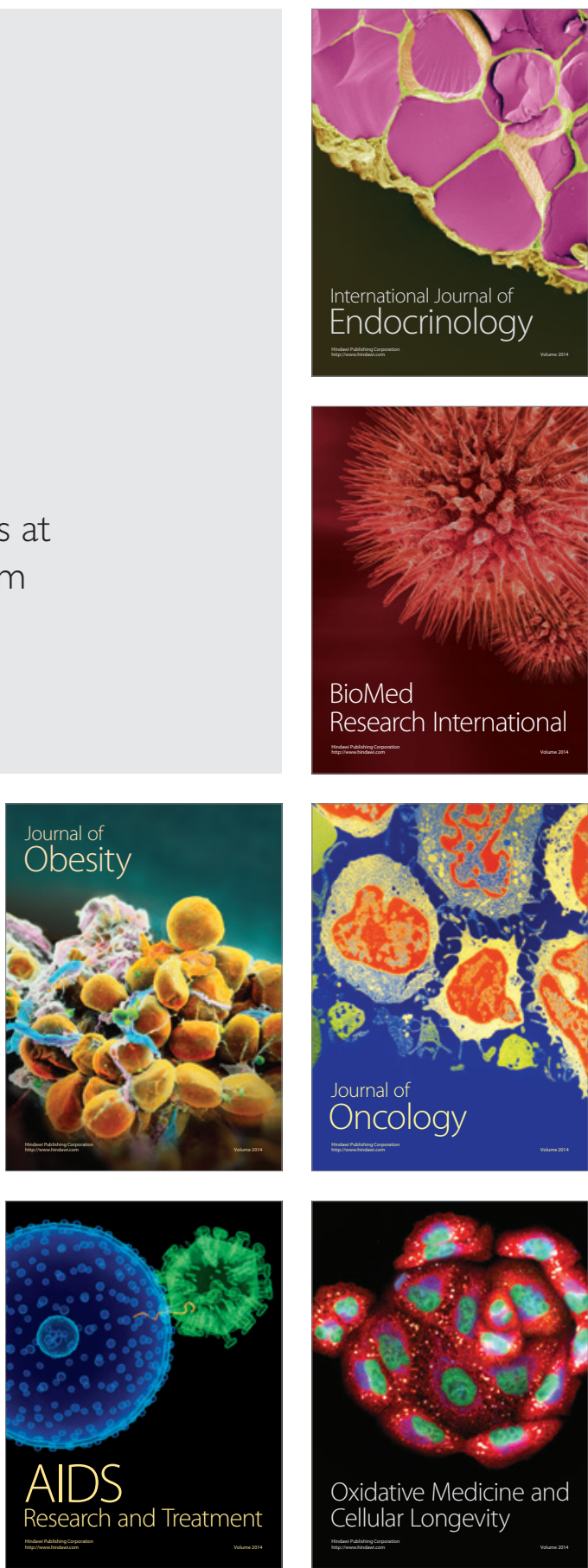